|EDITORIAL|

\title{
O Sistema Único de Saúde brasileiro: uma instituição em permanente embate
}

\section{The Brazilian Unified Health System: an institution in permanent conflict}

${ }^{1}$ Universidade Federal do Espírito Santo, Vitória/ES, Brasil.

\begin{abstract}
O atual momento de nosso país evoca o pensamento sobre o mundo, a vida (não apenas como vida orgânica), o homem, o Sistema Único de Saúde (SUS). Ao fazer isso, percebe-se que não se trata de coisas rígidas, imóveis. Todas podem ser entendidas como instituições que trazem em seu bojo tensões entre forças que podem nos levar, às vezes, por caminhos díspares, o que não significa dizer que haja uma permanência ao infinito entre um caminho e/ou outro¹.

O termo "instituição" não é uma expressão que tenha concordância a respeito de sua definição entre os diversos autores que tratam sobre o tema. É, no mínimo, uma palavra que gera muita discussão. Entre tantas definições, utiliza-se neste texto o pensamento de Gilles Deleuze $e^{2}$, que explica a instituição como um sistema organizado de meios para uma satisfação possível de necessidades. É um modelo positivo da ação, diferenciando-se da lei, que é uma limitação da ação.

A instituição, então, "remete a uma atividade social constitutiva de modelos, dos quais não somos conscientes, e que não se explica pela tendência ou pela utilidade, uma vez que esta última, como utilidade, pelo contrário, a supõe" (p. 135), restando explicitar o comentário do próprio Gilles Deleuze: "não basta dizer 'a instituição é útil', ainda é preciso indagar: a quem é útil?”2 (p. 135). Nesse sentido, a construção de instituições pelos homens está ligada à questão das exigências e dos interesses deles. Não se faz instituição que não se exija, ou seja, ela será útil para esses homens. Resta perguntar: a quais homens (éticos e não moralmente) ela estará servindo?
\end{abstract}

Instituições não são necessariamente terminadas, prontas, definitivas. Há um movimento permanente, há relações de forças, há imposições ao corpo do homem de uma série de modelos a seguir ${ }^{3}$. As instituições são constituídas pelos jogos entre forças desiguais, por meio das práticas - discursivas e não discursivas - do homem. Como em um jogo de força, sempre presente entre o molar e o molecular ${ }^{4}$.

Quando nos referimos ao termo instituições, estamos nos reportando, por exemplo, à religião, família, escola, saúde pública e ao SUS. Cada uma dessas instituições serve ao homem para certas necessidades. Assim, o SUS busca considerar nas formulações das políticas de saúde as demandas e necessidades da população ${ }^{5}$. Entendê-lo com todas as suas contradições e suas potências é importante e que pode ser feito e analisado como Instituição. 
As forças que constituem o SUS como instituição coexistem em relações desiguais e não necessariamente se excluem ou anulam; em suas relações produzem novas forças, encontros que lançam no mundo outros encontros, outras produções. Caminhos inesperados podem ser tomados. Aberturas para encontros potencializadores. Fluxos por vezes territorializantes, por vezes desterritorializantes. Fluxos que fazem conexões sem regras pré-determinadas. Conexões que seguem e fazem o curso da vida. Viva. Múltipla.

Jogos de forças fazem parte de qualquer instituição. Lutas, interesses, discussões políticas, visões e entendimentos diversos. As tensões entre todos esses elementos em suas virtualidades e atualidades remetem à construção do plano do possível' " "Não há objeto puramente atual. Todo atual se envolve de uma névoa de imagens virtuais"》 (p. 174). Essas tensões remetem a uma saúde que seja coletiva, não apenas pública, rompendo com inúmeras dicotomias, como: sujeitoobjeto, paciente-profissional da saúde, saúde-doença, indivíduo-sociedade, saúde física-saúde mental. Pode-se perceber que, para Deleuze e Guattarri ${ }^{8}$, o coletivo faz referência aos agenciamentos; já o privado trata de algo mais intimista, diferenciando-se dos pequenos grupos ou dos grandes conjuntos que participam e reterritorializam os sujeitos.

Jogos, movimentos dinâmicos colocam todo o aparato do SUS em constante análise. Pode-se pensar o SUS da mesma forma que Calvino ${ }^{9}$ descreveu a cidade de Zora, esquecida por não se modificar, por se tornar imóvel para facilitar sua memorização. Assim, se um dia o SUS se tornar imóvel e imutável para facilitar a memorização e seu entendimento, definhará, se desfará e desaparecerá.

É nessas relações dinâmicas que se modificam a todo instante, que está em jogo a tensão entre instituinte e instituído. Quando usamos esses termos, referimo-nos às tensões entre forças componentes de um mesmo campo e que não são contraditórias ou contrárias umas às outras. É na relação entre elas que a vida acontece. Trata-se de um puro plano de forças não valorativas.

Entretanto, faz-se necessário avaliar eticamente, a favor da vida, o que vem sendo produzido. É preciso ter certo cuidado para classificar as forças de instituintes ou instituídas. Corre-se o risco de criar um binarismo que não ocorre na vida, pois, por vezes, apenas se podem nomear as forças após certo tempo, após se ter mais clareza de como a força age, tendo assim maior clareza dos movimentos. O SUS entendido dessa maneira permite tomá-lo como uma série de conexões que vão se formando e se fazendo no decorrer de sua construção, na instantaneidade do cotidiano do trabalho.

Caminhos diversos, cruzamento de caminhos. Linhas que se unem e se separam. Linhas de fuga ${ }^{10}$, linhas duras, linhas de fronteira. É no funcionamento como rizoma ${ }^{10}$ que acontece no SUS. Esse sistema de saúde brasileiro é constituído por esse jogo de forças desiguais e por isso pode funcionar como um rizoma, dependendo da correlação de forças em cada momento. Configurações que alteram cada instante. Configurações que fazem as relações de forças evidenciarem momentos quentes e momentos frios ${ }^{12}$.

Assim, no SUS não há sujeitos nem objetos fixos, rígidos. Os sujeitos e objetos têm movimentos. Constituemse de matérias diferentemente formadas, de datas e velocidades diferentes. Crescem, rompem-se, tomam novos rumos em relação aos anteriormente trilhados. Há uma circularidade e alterações das situações que pairam na imanência dessas Instituições. Os sujeitos não são os mesmos nas diferentes situações em que a vida os coloca. Interferem e sofrem interferências. A cada ação, cada gesto, cada processo de desterritorialização, o sujeito pode se transformar. Porém, para que essa transformação ocorra é necessário que haja algum grau de abertura para se afetar pelo que nos separa dos clichês, das ideias prontas e uniformizadas. A desterritorialização ocorrerá quando de fato houver certa abertura desses sujeitos para buscar-se viver, produzir novas situações, novos sujeitos ${ }^{10}$.

No SUS, a tensão entre instituinte e instituído resulta em algumas lutas. E, em determinadas situações, transvertem-se em outras reivindicações. Por exemplo, na luta pela desinstitucionalização que, por vezes, em alguns locais, a partir de alguns atores, transforma-se em um movimento de desospitalização, mas com a continuidade das relações de exclusão ${ }^{11}$.

Para que haja efeito, para que se produzam transformações significativas na sociedade, transformações micropolíticas $^{13}$. São necessárias microrevoluções que colocam novos agenciamentos em funcionamento. Devires 
que hão de vir! É imprescindível que haja a postura e a ética necessária para que não ocorra a despotencialização dos agenciamentos. Os modos de estar na vida devem procurar potencializar os agenciamentos que produzem desvios das rotas pré-estabelecidas que não tenham (ou têm) gerado coisas boas (bons encontros) ${ }^{14}$. 'Forçar' a vida a se conectar com outros agenciamentos.

O SUS entendido como um sistema que faz inúmeras conexões, com as mais diferentes linhas da vida, configura-se de maneira bastante inusitada, potencializando o devir, abrindo espaço para o inesperado, para a criação, para movimentos potentes de produção de saúde ainda não institucionalizados.

Esses movimentos são dificultados nos momentos em que há um gerenciamento de modo fechado nas ações institucionalizadas, burocratizando o sistema com Leis rígidas, limitando as ações inventivas dos profissionais e outros atores que compõem o rizoma.

No atual momento, entendemos que uma excelente maneira de produção de saúde é aproveitar a potência dos profissionais, das equipes e dos serviços para criar ações as quais ultrapassem o cumprimento restrito de normas e diretrizes. É preciso que a invenção seja colocada em prática para que as atuais (e reais) necessidades da população sejam atendidas. As diretrizes do SUS não podem ser entendidas como algemas que limitam e estabelecem ações rígidas, padronizadas. É preciso tê-las como direções a serem tomadas, direções norteadoras, rumos possíveis, porém rumos em campos abertos que possibilitem inclusive o surgimento de novos serviços, novos projetos, novas pesquisas no âmbito do SUS brasileiro.

\section{REFERÊNCIAS |}

1. Silva ALA. Produção de subjetividade e gestão em saúde: cartografias da gerência. Campinas. Tese [Doutorado em Saúde Coletiva] - Universidade Estadual de Campinas; 2004.

2. Deleuze G. Instintos e instituições. In: Escobar CH. Dossiê Deleuze. Rio de Janeiro: Hólon Editorial; 1991. p. 134-7.

3. Lourau R. Uma apresentação da análise institucional. In: Lourau R. A análise institucional. Petrópolis: Vozes; 1995. p.128-40.

4. Deleuze G, Guattari F. Mil platôs: capitalismo e esquizofrenia. Rio de Janeiro: 34; 2004. p. 83-116. v. 3.

5. Santos NR. SUS 30 anos: o início, a caminhada e o rumo. Ciênc Saúde Coletiva. 2018; 23(6):1729-36.

6. Lavrador MCC. Loucura e vida na contemporaneidade. Vitória. Tese [Doutorado em Psicologia] - Universidade Federal do Espírito Santo; 2006.

7. Deleuze G, Parnet C. Diálogos. São Paulo: Escuta; 1998.

8. Deleuze G, Guattari F. Mil platôs: capitalismo e esquizofrenia. Rio de Janeiro: 34; 2004. p. 9-30. v. 3.

9. Calvino I. As cidades invisíveis. São Paulo: Companhia das Letras; 1990.

10. Deleuze G, Guattari F. Mil platôs: capitalismo e esquizofrenia. Rio de Janeiro: 34; 2004. p. 11-38. v. 1.

11. Amarante P, Nunes MO. A reforma psiquiátrica no SUS e a luta por uma sociedade sem manicômios. Ciênc Saúde Coletiva. 2018; 23(6):2067-74.

12. Rodrigues HBC. Análise institucional francesa e transformação social: o tempo (e contratempo) das intervenções. In: Rodrigues HBC, Altoé S, organizadores. SaúdeLoucura. São Paulo: Hucitec; 2004. p. 115-64.

13. Guattari F. Revolução molecular: pulsações políticas do desejo. São Paulo: Brasiliense; 1977. p. 191-210.

14. Deleuze G. Espinosa: filosofia prática. São Paulo: Escuta; 2002.

6 | Rev. Bras. Pesq. Saúde, Vitória, 21(3): 4-6, jul-set, 2019 